\title{
Rectal temperature of normal babies the night after first diphtheria, pertussis, and tetanus immunisation
}

\author{
D Rawson, S A Petersen, M P Wailoo
}

\begin{abstract}
Continuous rectal temperature recordings were made from 32 babies the night after their first diphtheria, pertussis, and tetanus immunisation and compared with recordings made before immunisation. Tog values of clothes and wrapping and room temperatures were also recorded. We found that immunisation the day before disturbs the normal night time rhythm of deep body temperature. The rectal temperature of immunised babies was significantly higher than non-immunised babies from two hours into the night. We also found that there were considerable individual variations in the extent of disturbance of temperature rhythm. They were not correlated with thermal environment. There is no reason to suppose that these mild physiological responses to immunisation are in any way harmful.
\end{abstract}

Babies aged 3-4 months exhibit a characteristic pattern of rectal temperature change during a night's sleep, ${ }^{1}$ which is maintained across a very wide range of parental practice of room heating, clothing, and wrapping, ${ }^{2}$ indicating a considerable capacity for thermoregulation. Although this rhythm is very resistant to disturbance by changes in thermal environment, it may be affected by changes within the baby, such as a developing infection, and it has been suggested that under these conditions a warm environment may be less tolerable. ${ }^{3}$

Nearly all babies receive their first diphtheria, pertussis, and tetanus (DPT) immunisation at about this age, which provides an opportunity to study the effects on body temperature of a standardised dose of an infective agent administered at a known time to babies who will subsequently sleep under a wide range of different thermal conditions. While it is known that some babies show a small rise of body temperature the night after immunisation, ${ }^{4}$ there are no reports of continuous records of body temperature, or the effects of different thermal environments on the response. In this paper we report on the changes in rectal temperature of babies sleeping at home the night after their first DPT immunisation, and relate changes in body temperature to thermal environment.

\section{Methods}

A random sample of 31 babies due for their first DPT immunisation was recruited by liaison with general practitioners in Leicester. They were visited on a night before immunisation, and basic perinatal data recorded, together with naked body weight, skinfold thickness, and head circumference. Thermistor probes were then attached to the babies, and rectal temperature (soft probe $5 \mathrm{~cm}$ from the anal margin), skin temperature on the abdomen $(2 \mathrm{~cm}$ - left of the umbilicus), and skin temperature on the forehead were recorded. A fourth probe measured room temperature by the cot side. All probes were connected to a Grant Squirrell data logger set to record once a minute throughout the night. These recording techniques have all be validated, and shown to be safe. ${ }^{1}$ Full ethical committee approval was obtained for the study.

Note was made of each item of clothing and wrapping used by parents and a tog value calculated according to formulas supplied by the Shirley Institute, Manchester. The parents were also asked to maintain a diary of the night's events, including feeds, and times at which they were disturbed by the baby.

The recording was repeated the night after immunisation and the family contacted one week later to check on the health of the baby.

The data from the logger were read into a computer and scrutinised for evidence of technical problems, such as loss of probes. Only unblemished data were analysed. In this paper we report on the rectal temperatures. For each night of successful recording, rectal temperature was abstracted at 30 minute intervals from one hour before bedtime till nine hours later. Data at each time point from different babies before and after immunisation were analysed to yield mean rectal temperature and its standard error.

\section{Results}

Of the 31 subjects studied 17 were boys and 14 girls. The average (SEM) age at immunisation was $15.03(0.79)$ weeks. Only four babies were older than 16 weeks. Eight of the babies were immunised between 09.00 and 10.00 , the remainder between 14.00 and $16 \cdot 00$. The mean maternal age was $28.56(1.06)$, and the social class distribution resembled that of the general Leicester population. All but one of the babies slept in their own cots, mostly in a separate room. The recordings were made during spring and summer 1989, and the maximum room temperature at night averaged $21.97(0.98)^{\circ} \mathrm{C}$ before and $23.24(0.68)^{\circ} \mathrm{C}$ after immunisation. The minimum room temperature was 18.95 $(0.78)^{\circ} \mathrm{C}$ before " and $19.47 \quad(0.42)^{\circ} \mathrm{C}$ after immunisation. Babies were clothed and wrapped with $10.36(0.91)$ tog units (range 

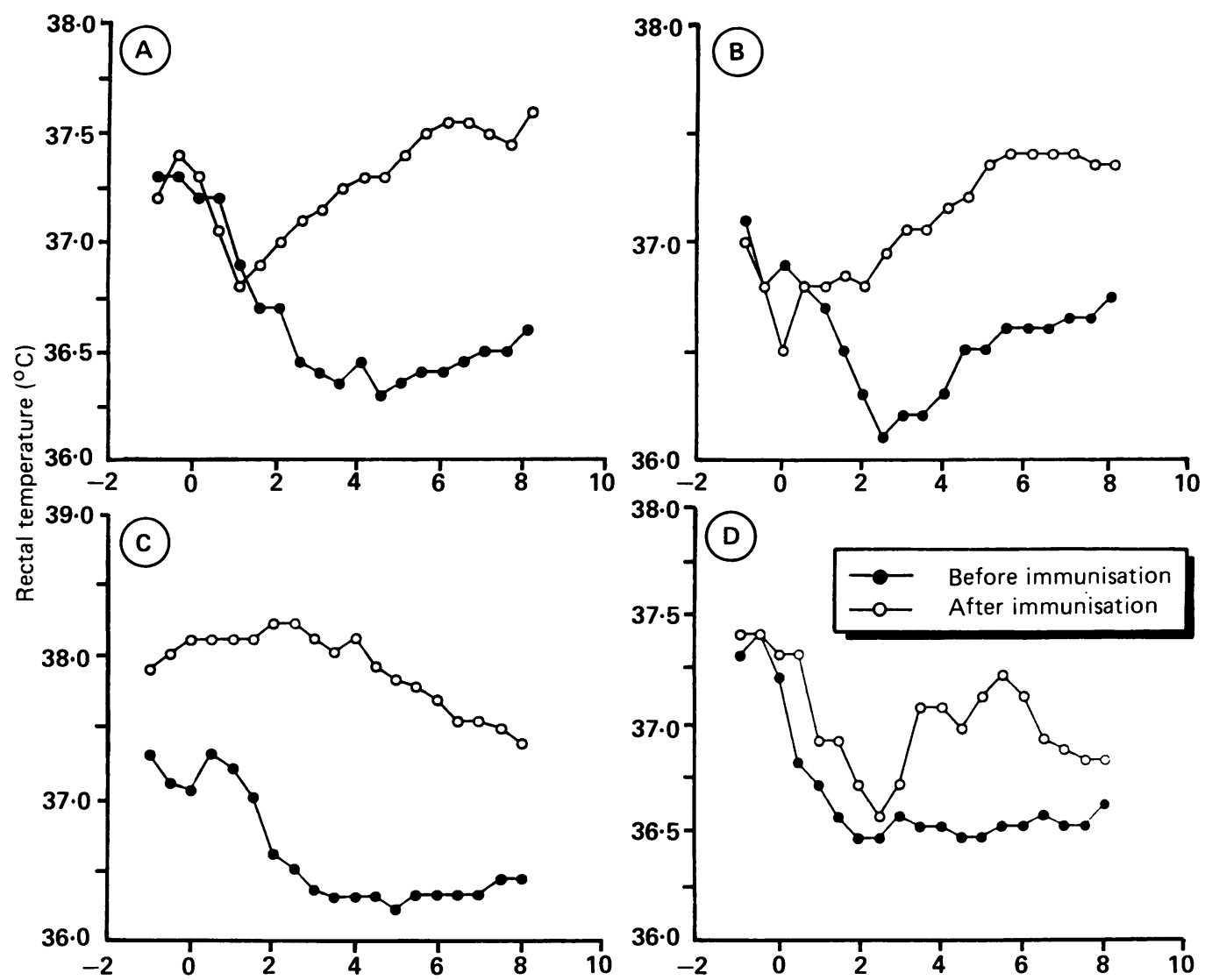

Figure 1 The rectal temperatures of four babies during the night before and after the first DPT immunisation.

$4 \cdot 6-15 \cdot 9)$ before and $9 \cdot 48(0.63)$ units (range $3 \cdot 2-17 \cdot 0)$ after immunisation. There were no significant differences in thermal environment between recordings before and after immunisation.

Figure 1 shows typical individual records of rectal temperature over the nights before and after immunisation. The most common pattern of temperature change after immunisation is that shown in $1 \mathrm{~A}$ and $1 \mathrm{~B}$. Before bedtime the rectal temperature is the same as a normal night, and after bedtime the temperature begins to fall, but after an hour or two it rises again to levels well above those before immunisation. One baby had a raised rectal temperature at

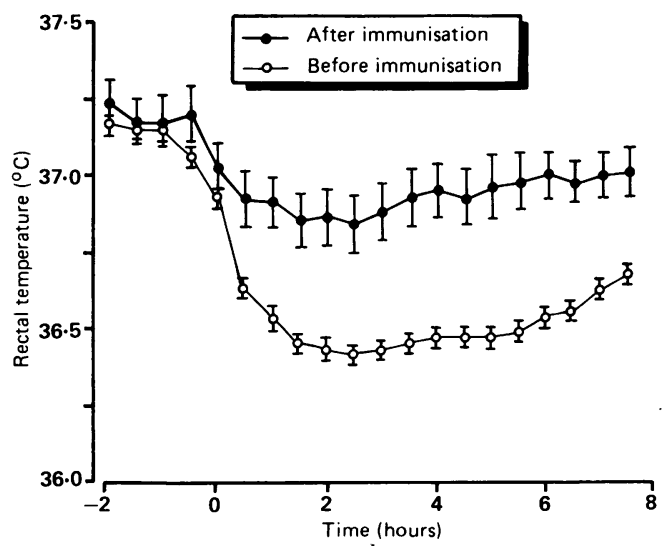

Figure 2 The mean rectal temperature of babies during the night after the first DPT immunisation compared with that during the night before immunisation. Bars show SEM. bedtime, which was maintained throughout the night (fig 1C). Six babies showed no differences between temperature patterns before and after immunisation.

Figure 2 shows figures averaged before and after immunisation. The curve before immunisation is indistinguishable from those that we have reported earlier in normal infants, but after immunisation rectal temperature was significantly higher than before from two hours after bedtime until seven hours later.

At bedtime the rectal temperature before immunisation was $37 \cdot 18(0.03)^{\circ} \mathrm{C}$ and after $37 \cdot 18(0.08)^{\circ} \mathrm{C}$. Four hours later it was 36.43 $(0.07)^{\circ} \mathrm{C}$ before and $36.93(0.09)^{\circ} \mathrm{C}$ after

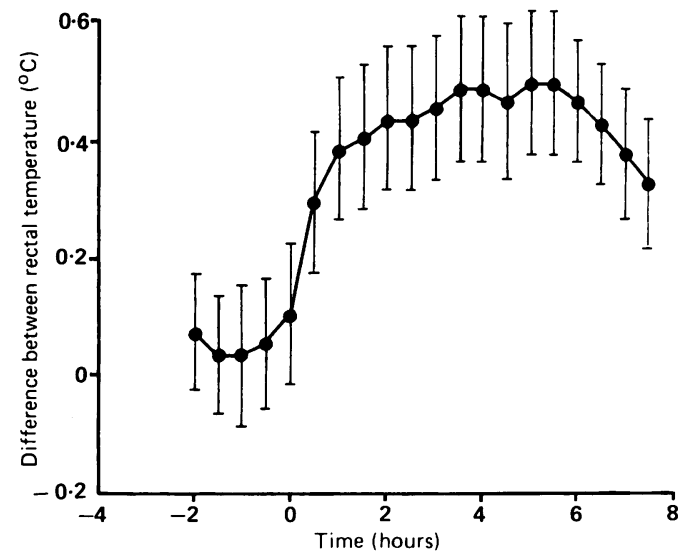

Figure 3 The differences between babies' rectal temperatures at various times during the night before and after first DPT immunisation. Bars show SEM. 
immunisation. The differences between the means before and after were significant $(p<0.01$ at least by $t$ test) from two hours after bedtime (fig 3). The median rectal temperature four hours after bedtime was $36.78^{\circ} \mathrm{C}$ after immunisation. Those babies above median rectal temperature were not in significantly warmer rooms, nor were they significantly more insulated by clothing and wrapping. The babies whose temperature exceeded $37 \cdot 3^{\circ} \mathrm{C}$ were also not in warmer rooms, or more insulated than the rest. Those above median rectal temperature were, however, of significantly lower birth weight $(p<0.02$, Student's $t$ test with $29 \mathrm{df})$ and tended to come from social classes IV and $V$. There was no difference in temperature pattern between babies immunised in the morning or afternoon.

Some of the babies were reported by their parents to have a 'disturbed night' after immunisation, but, on average, the babies did not disturb their parents more often the night after immunisation. Nor were they fed more often.

Five of the babies were given paracetamol (as either Calpol or Disprol) during the evening or night. The rectal temperature of the treated babies was not higher than the others either before or after the medication.

\section{Discussion}

Immunisation, a highly standardised infective challenge, leads to a disturbance of the normal night time rhythm of deep body temperature in most babies, though the extent of the change varies between individuals.

Rectal temperature was not significantly different in non-immunised and immunised babies in nearly all cases at bedtime but, after initially falling as expected, rose to waking levels or above within a few hours. By four hours into the night half the babies were over two standard deviations above the mean rectal temperature of non-immunised babies at that time. The disturbance of the normal temperature rhythm seems to be a response to the immunisation, occurring only during the first night irrespective of the time of immunisation the previous day. In the few cases where we have monitored temperature during second and subsequent nights, no changes in temperature have been observed, though this work is still in progress and will be reported later. It is likely that central thermal control is affected, perhaps by a combination of systemic 'infection' and a local inflammatory response at the injection site, though it should be noted that the immunised babies did not become febrile, and there is no reason to suppose that the physiological response to immunisation reported here is any way harmful. We have observed a similar pattern of temperature change in babies who were thought to be in the early stages of a minor infection.

This rise of temperature was not merely the consequence of a 'disturbed night'. Overall, the babies did not disturb their parents more often the night after immunisation than before, though the two whose rectal temperature was highest were disturbed. Furthermore, our previous work shows that a disturbed night per se does not normally alter the rhythm of body temperature. ${ }^{5}$

The individual differences in temperature change the first night do not seem to be explained by different thermal environments. Those who showed the largest disturbance of temperature rhythm were not more heavily wrapped or in warmer rooms, despite the fact that some very high room temperatures (up to $28^{\circ} \mathrm{C}$ ) were recorded in a hot summer.

The babies whose temperature rise was above median were, however, of lower birth weight suggesting that some feature of the baby rather than the environment determines the extent of temperature rise. Maybe the thermal response to immunisation provides a means of assessing the way babies will respond to other infective challenges.

The Trent Regional Health Authority is thanked for support.

1 Wailoo MP, Petersen SA, Whittaker H, Goodenough P. Sleeping body temperatures in 3-4 month old infants. Arch Dis Child 1989;64:596-9.

2 Wailoo MP, Petersen SA, Whittaker H, Goodenough P. The thermal environment in which $3-4$ month old infants sleep at home. Arch Dis Child 1989;64:600-4.

3 Stanton AN. Over heating and cot death. Lance 1984;ii: 1199.

4 Waight PA, Pollock TM, Miller E, Coleman EM. Pyrexia after DPT and DT vaccines. Arch Dis Child 1983;58:92133.

5 Wailoo MP, Petersen SA, Whittaker H. Disturbed nights in 3-4 month old infants- the effects of feeding and thermal environment. Arch Dis Child 1990;65:499-501. 